\title{
MR Imaging of Carcinoma Cervix
}

\author{
Narender reddy Peddareddy ${ }^{1}$, Santhosh Babu Rendla ${ }^{1}$, \\ Sumalatha Kasturi ${ }^{2}$ and Narender Gajula ${ }^{3}$ \\ ${ }^{1}$ Assistant Professor, Department of Radiodiagnosis, Chalmeda Anand rao Institute of Medical \\ Sciences, Karimnagar, Telangana State, India \\ ${ }^{2}$ Assistant Professor, Department of Pathology, Chalmeda Anand rao Institute of Medical \\ Sciences, Karimnagar, Telangana State, India \\ ${ }^{3}$ Assistant Professor, Department of Dermatology, Chalmeda Anand rao Institute of Medical \\ Sciences, Karimnagar, Telangana State, India
}

*Corresponding author

\section{Keywords}

Carcinoma cervix, MRI, CT scan, Staging.

\begin{tabular}{l}
\hline Article Info \\
\hline Accepted: \\
20 June 2016 \\
Available Online: \\
10 July 2016
\end{tabular}

\section{A B S T R A C T}

Carcinoma of cervix accounts for $25-50 \%$ of total cancers and for $86-90 \%$ of all genital cancers in Indian women. Accurate staging of uterine cervical carcinoma is crucial in determining the mode of treatment. Clinical staging based primarily on pelvic examination, cystoscopy and proctoscopy is inaccurate and surgical staging for clinical stages II to IV generally is not routinely performed and has significant morbidity. For these reasons, CT and MR imaging may become a more accurate substitute for clinical staging of cervical carcinoma. The purpose of the study is to compare CT and MRI findings, in the evaluation and staging of uterine cervical carcinoma. Patients presenting to the departments of Oncology \& gynecology, Chalmeda Anandrao Medical College Hospital and Cancer Hospital, Karimnagar with clinical suspicion of uterine cervical carcinoma were included in this study. The number of patients included in the study were twenty. In our study all the patients underwent both MR and CT imaging. Overall, the accuracy rates of CT and MR imaging for pelvic lymph node metastasis were equal in our study. The age of the patients ranged from 40 to 63 years with mean age being 48 years. The peak incidence was seen in the age group of $45-50$ years. One of advantages of MR is in its ability to pick up lesions very early as compared to CT. Both MR and CT picked up all the lesions in our study .The accuracy of parametrial evaluation of CT was much less when compared to MR imaging. CT could not differentiate between the central tumor mass and the irradiated uterus. This was better seen on MR imaging which again has the ability to differentiate between fibrosis and recurrence. MR imaging should be used as routine for imaging study for preoperative staging of uterine cervical carcinoma. 


\section{Introduction}

The proverb that "Prevention is always better than cure" is absolutely valid for the disease of carcinoma of uterine cervix, which was a well known disease in India and Egypt even before the birth of Christ. The disease has gained great importance in last half of the $20^{\text {th }}$ century because of the availability of facilities of its early detection and treatment. Carcinoma of cervix is the second most common cancer in women worldwide today. In India, the annual incidence of carcinoma of cervix is estimated to be five lakh new cases per year. Carcinoma of cervix accounts for $25-50 \%$ of total cancers while for $86-90 \%$ of all genital cancers in Indian women (Parkin et al., 1990; Whelan et al., 1990). Uterine cervical carcinoma is one of the most frequent causes of death in women. Accurate staging of uterine cervical carcinoma is crucial in determining the mode of treatment.

There is a potential role for accurate noninvasive staging of cervical carcinoma. This is because clinical staging based primarily on pelvic examination, cystoscopy, and proctoscopy is inaccurate, and because surgical staging for clinical stages II to IV generally is not routinely performed and has significant morbidity. Up to $12 \%$ of patients with clinical stage I disease will have a planned hysterectomy aborted by intra operative findings, usually gross extension of pelvic disease or periaortic lymphadenopathy (Piver et al., 1975).

Patients treated with radiation therapy only, for example those with stage II and III, may be under stage or over stage, with effects on mortality (Fagundes et al., 1992). For these reasons, CT and MR imaging may become more accurate substitute for clinical staging of cervical carcinoma.
The purpose of the study is to compare CT and MRI findings, in the evaluation and staging of uterine cervical carcinoma with special emphasis on detection of earliest lesion, parametrial assessment, early vaginal and uterine invasion, urinary bladder and rectal invasion and post radiotherapy changes like fibrosis and recurrence.

\section{Materials and Methods}

Patients presenting to the departments of Oncology \& gynaecology, Chalmeda Anandrao Medical College Hospital and Cancer Hospital, Karimnagar with clinical suspicion of uterine cervical carcinoma were included in this study. The number of patients included in the study were twenty.

\section{CT Techniques}

CT Images of the pelvis will be obtained on a Toshibha, Asteion TSX -021A Spiral CT unit. Matrix size of $512 * 512$ and slice section of $10 \mathrm{~mm}$.

\section{MR Imaging Technique}

MRI was performed on the 1.5 Tesla system (GE Healthcare) using a pelvic array coil for the pelvic scan and a torso phased-array coil for the paraaortic scan.

\section{Results and Discussion}

Patients presenting to the departments of Oncology \& gynecology, Chalmeda Anandrao Medical College Hospital and Cancer Hospital, Karimnagar with clinical suspicion of uterine cervical carcinoma were included in this study. The number of patients included in the study were twenty. In our study all the patients underwent both MR and CT imaging. 
From December 2007 to September 2009, twenty two patients diagnosed of cervical carcinoma were examined with both CT \& MR imaging at our hospital. Uterine cervical carcinoma was diagnosed histologically in nineteen patients. The other three patients were previously diagnosed cases of carcinoma, out of which two had undergone hysterectomy and one had radiation therapy. They were referred with a suspicion of recurrence.

The ages of the patients ranged from 40 to 63 years (mean, 48 years) with peak incidence being in the age group of $45-50$ years (Table-I). This data is agreed by most of the previous studies done earlier.

CT staging and MR staging were based on previously reported criteria (Table-II).

\section{Tumor detection}

In our study tumor was visible in all the cases both on CT and MR images probably because the size of the tumor was big enough by the time of diagnosis. On T2 weighted images, twenty tumors showed higher signal intensity than did normal cervical stroma. On CT, tumors appeared isodense or mixed dense with the cervical stroma, and bulky cervix.

\section{Parametrial evaluation}

In a study done by Vick et al., (1984) which included sixteen patients of newly diagnosed cases of cervical carcinoma, false positive cases of parametrial involvement was high on CT when the criteria of prominent parametrial strands were used as compared to the irregular lateral cervical margins and parametrial mass. The accuracy rate was only $58 \%$. In another study conducted by Seung Hyup Kim et al., (1990) which included thirty patients diagnosed of uterine cervical carcinoma, comparison of CT and MR findings were done. Twelve patients had parametrial involvement out of which MR had an accuracy of $92 \%$ as compared to $70 \%$ of CT. In our study parametrial involvement was seen in seven patients at CT, out of which three cases showed intact cervical stroma on MR and four patients showed parametrial involvement at MR imaging, suggesting three false-positive cases detected on CT (Table- III). This is a significant finding for the staging will be altered and so is the treatment.

\section{Staging}

In a study conducted by Seung Hyup Kim et $a l$, the overall accuracy in tumor staging was $63 \%$ for CT and $83 \%$ for MRI as compared to clinical staging. The downstaging rate was $10 \%$ and upstaging rate was $27 \%$ for CT. In another study done by Kim SH et al., (1993) in ninety nine patients of cervical carcinoma MRI was superior in over all staging with $77 \%$ accuracy as compared with $69 \%$ accuracy on CT. In our study which consisted of twenty two patients nine patients were staged as Stage IB, one case each of Stage IIA and Stage IIB, seven cases of Stage IVA and three cases of stage IVB. CT over-estimated the staging in four cases as compared to MRI by suggesting parametrial involvement in three cases and bladder involvement in another case, which on MR imaging were staged correctly due to the presence of the intact stromal ring and well preserved perivesical plane.

In three cases CT under staged the case because vaginal extension in one case, bladder extension in one case and rectal extension in another case was not detected. Vaginal extension was detected on MRI in the sagittal images involving the anterior wall of vagina. Rectal and bladder 
involvement was detected on MR imaging by effacement of perirectal and periveiscal fat plane. Hence the downstaging percentage on $\mathrm{CT}$ was $18 \%$ and upstaging percentage was $13 \%$ which differs from the study done by Seung Hyup Kim et.al [6] probably because of comparison with clinical staging and also due to Stage I cases being more in their study. The accuracy of $\mathrm{CT}$ in staging of cervical carcinoma is only $72 \%$ in our study which is almost same compared with the study done by Kim SH et al., (1993).

\section{Uterine evaluation}

In our study a total of eight cases of uterine extension were found in our study of which CT missed to pickedup in one case, which was visualised on MRI (Table-IV). In a study done by Mitchell DG, Synder B et al., (2006) in 208 patients biopsy proven invasive cervical carcinoma. They concluded MRI is superior to CT for evaluating uterine body invasion.

\section{Lymph node evaluation}

In our study only two case of pelvic lymph nodal involvement was seen and it was detected on both $\mathrm{CT}$ and $\mathrm{MR}$ imaging (Table-VIII). One more case of inguinal lymph node was seen and again it was detected on both CT and MR imaging. However, in previous studies done by James W Walsh and Dean R Goplerud (1981); Kim SH, et al., (1990); Togashi K, et al., (2006); Bellomi M, et al., (2005) the accuracy of detection of lymph node involvement by $\mathrm{CT}$ and MRI was almost same and probably because the size of the lymph node is taken as the criteria. Although detection will help in proper treatment planning the detection of lymph node involvement will not change the staging.

Table.1 Age Distribution of cervical carcinoma

\begin{tabular}{|c|c|}
\hline Age & No. of Patients \\
\hline $40-45$ & 4 \\
\hline $46-50$ & 7 \\
\hline $51-55$ & 4 \\
\hline $56-60$ & 4 \\
\hline $61-65$ & 3 \\
\hline
\end{tabular}

Age distribution chart shows the average age of incidence of carcinoma cervix in this study was between 40 to 65 years with peak incidence between 46 to 50 years.

Table.2 Staging of carcinoma cervix

\begin{tabular}{|c|c|}
\hline Stage & No. of Patients \\
\hline Stage IB & 9 \\
\hline Stage IIA & 1 \\
\hline Stage IIB & 1 \\
\hline Stage III & 0 \\
\hline Stage IVA & 8 \\
\hline Stage IVB & 3 \\
\hline
\end{tabular}

In this study most of the cases were of stage IB with stage IVA being the next common stage. Only one case each of Stage IIA and IIB were seen. 
Table.3 Detection of Uterine Extension

\begin{tabular}{|c|c|c|}
\hline $\begin{array}{c}\text { No. of cases of } \\
\text { Uterine Extension }\end{array}$ & $\begin{array}{c}\text { No. of cases Detected by } \\
\text { MRI }\end{array}$ & $\begin{array}{c}\text { No. of cases } \\
\text { Detected by CT }\end{array}$ \\
\hline 8 & 8 & 7 \\
\hline
\end{tabular}

A Total of eight cases of uterine extension were found in our study of which CT scan missed to picked up one case, which was visualised on MRI

Table.4 Detection of Bladder Extension

\begin{tabular}{|c|c|c|}
\hline $\begin{array}{c}\text { No of cases of } \\
\text { Bladder Extension }\end{array}$ & $\begin{array}{c}\text { No of cases Detected by } \\
\text { MRI }\end{array}$ & $\begin{array}{c}\text { No of cases Detected } \\
\text { by CT }\end{array}$ \\
\hline 8 & 8 & 7 \\
\hline
\end{tabular}

A total of eight cases of bladder extension were found in this study with MRI picking up all the eight cases but CT missed one case.

Table.5 Detection of Rectal Extension

\begin{tabular}{|c|c|c|}
\hline $\begin{array}{c}\text { No of cases of Rectal } \\
\text { Extension }\end{array}$ & $\begin{array}{c}\text { No of cases Detected by } \\
\text { MRI }\end{array}$ & $\begin{array}{c}\text { No of cases Detected } \\
\text { by CT }\end{array}$ \\
\hline 4 & 4 & 3 \\
\hline
\end{tabular}

Rectal extension was seen in four cases in this study which was detected by MRI but CT failed to detect in one case.

Table.6 Detection of Parametrial Extension

\begin{tabular}{|c|c|c|c|}
\hline $\begin{array}{c}\text { No. of cases of } \\
\text { Parametrial } \\
\text { Invasion }\end{array}$ & $\begin{array}{c}\text { No. of cases Detected by } \\
\text { MRI }\end{array}$ & \multicolumn{2}{|c|}{ No of cases Detected by } \\
\cline { 3 - 4 } & & $\begin{array}{c}\text { False } \\
\text { positives }\end{array}$ & $\begin{array}{c}\text { True } \\
\text { cases }\end{array}$ \\
\hline 4 & 4 & 3 & 4 \\
\hline
\end{tabular}

In this study a total of four cases of parametrial invasion were found and MRI detected all the cases. CT showed seven cases out of which three were false positives. 
Table.7 Detection of Vaginal Extension

\begin{tabular}{|c|c|c|}
\hline $\begin{array}{c}\text { No of cases of } \\
\text { vaginal extension }\end{array}$ & $\begin{array}{c}\text { No of cases Detected by } \\
\text { MRI }\end{array}$ & $\begin{array}{c}\text { No of cases Detected by } \\
\text { CT }\end{array}$ \\
\hline 4 & 4 & 3 \\
\hline
\end{tabular}

Vaginal involvement was seen in four cases out of which CT missed to pick up in one case which was visualized on MRI.

Table.8 Detection of Lymph Node Extension

\begin{tabular}{|c|c|c|}
\hline $\begin{array}{c}\text { No of cases of } \\
\text { lymph node } \\
\text { involvement }\end{array}$ & $\begin{array}{c}\text { No of cases Detected by } \\
\text { MRI }\end{array}$ & $\begin{array}{c}\text { No of cases Detected } \\
\text { by CT }\end{array}$ \\
\hline 3 & 3 & 3 \\
\hline
\end{tabular}

Three cases of lymph node involvement was seen in this study which was detected both by MRI and CT. In two cases pelvic lymph nodes were involved and in another case inguinal lymph node involvement was detected.

Table.9 Detection of Metastasis

\begin{tabular}{|c|c|c|}
\hline $\begin{array}{c}\text { No of cases with } \\
\text { metastasis }\end{array}$ & $\begin{array}{c}\text { No of cases Detected by } \\
\text { MRI }\end{array}$ & $\begin{array}{c}\text { No of cases Detected } \\
\text { by CT }\end{array}$ \\
\hline 1 & 1 & 1 \\
\hline
\end{tabular}

In this study only one case of metastasis was detected and it was to the liver. It was detected by both MRI and CT.

Fig.1,2 Ca. Cervix post radiotheraphy recurrence better demonstrated on MRI compared to CT

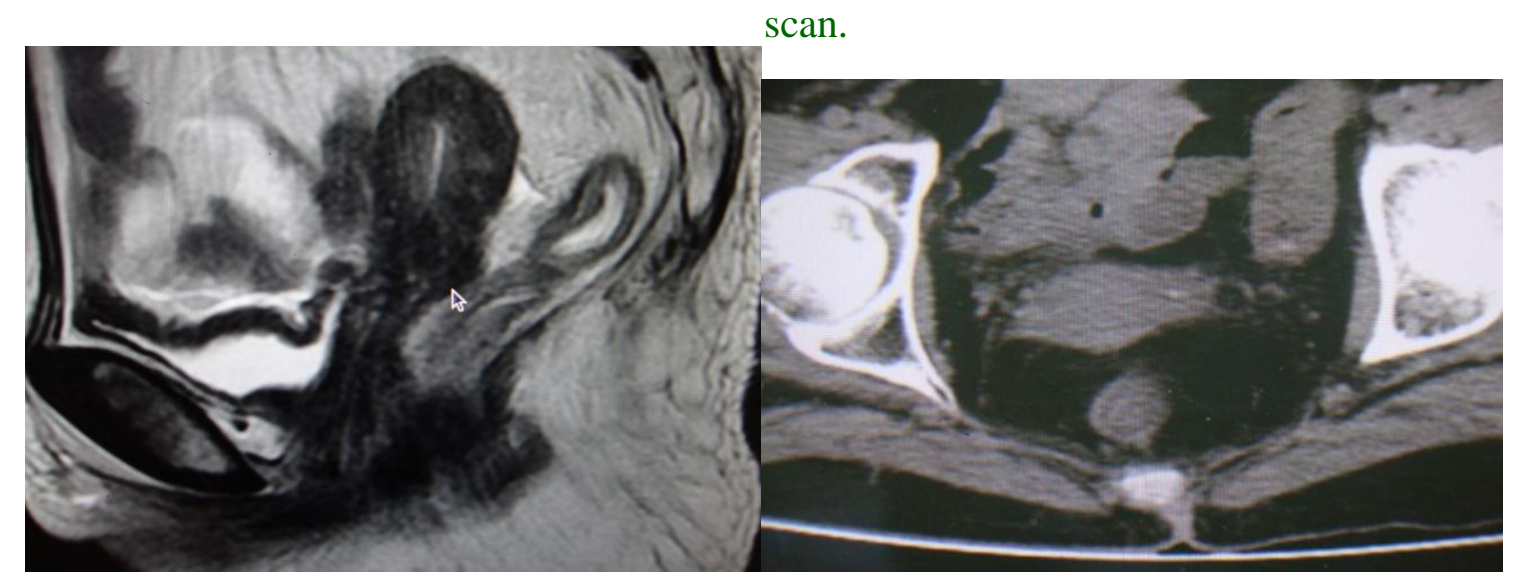


Fig.3,4 CT and MRI showing carcinoma cervix involving bladder, rectum, uterus, vagina and pelvic nodes (stage IVA).
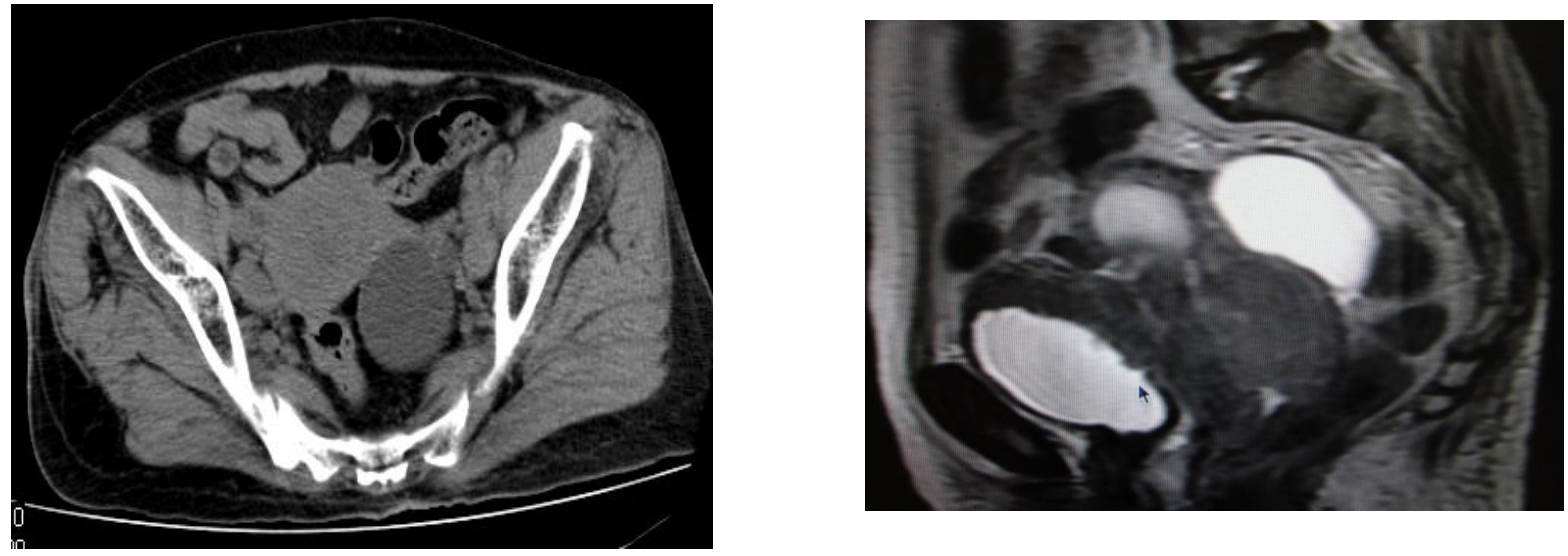

Fig.5,6 Ca. Cervix stage IIA - CT showing parametrial extension (false +Ve) but not on MRI.

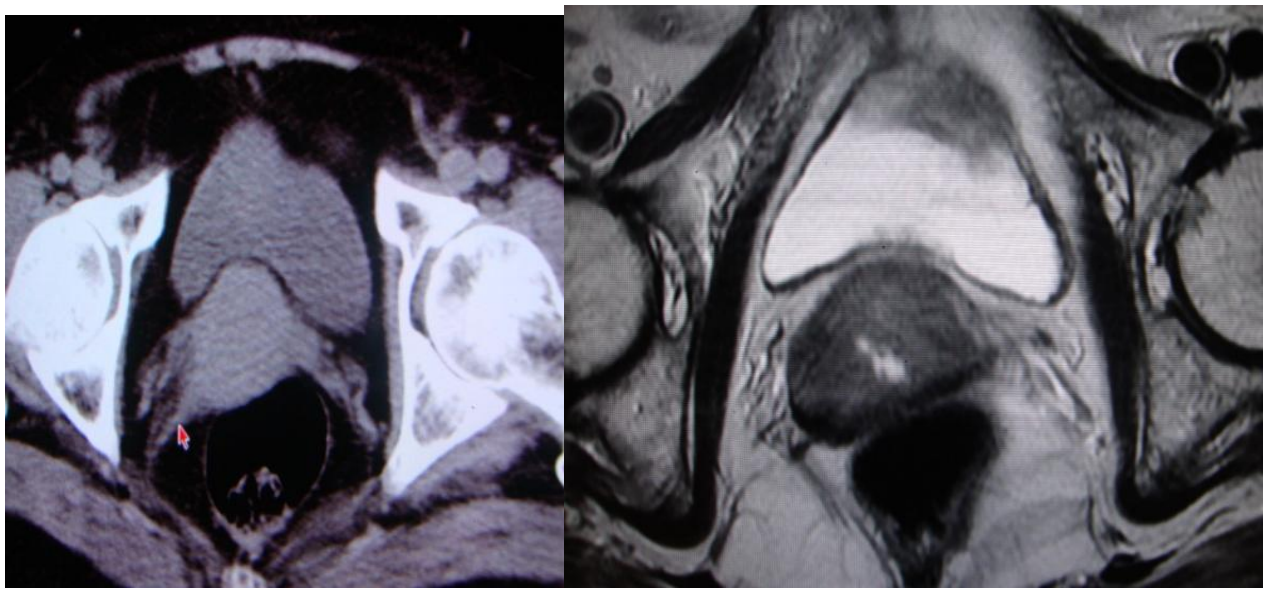

\section{Metastasis}

In our study we had only two cases of distant metastasis one involving the liver and the other involving the inguinal lymph node (Table-IX). However, inguinal lymph node involvement is seen. In a study done by Walsh and Goplerud (Walsh et al., 1981) in seventy five patients with diagnosis of cervical carcinoma, two cases were having inguinal lymph node involvement.

\section{Recurrent Tumor}

In our study two cases of post operative recurrence were seen and one case of post radiation therapy was seen. One case each of post radiation therapy recurrence and post operative recurrence case were staged at IVA both by CT and MR imaging. One more case of post operative recurrence was staged as IB. However, CT could not differentiate an irradiated uterus from central tumor recurrence which was better appreciated at MR imaging (Van Nagell et al., 1979). Misciasi T et al., (2004) analyzed the CT and MRI on follow up a patient with recurrent cervical carcinoma treated with radiotherapy, they concluded MRI is the procedure of choice in follow up. 
In conclusion, MR imaging is superior to CT in the evaluation of parametrial status. Overall, the accuracy rates of CT and MR imaging for pelvic lymph node metastasis were equal in our study. MR imaging has the ability to differentiate between fibrosis and recurrence in post radiotherapy cases.

MR imaging has several other advantages over CT, such as high-contrast resolution and multiplanar capability which usually demonstrate well the relationship of the uterus, the vagina, the urinary bladder, and the rectum on sagital images. We conclude that MR imaging should be used as routine for imaging study for preoperative staging of uterine cervical carcinoma.

\section{References}

Bellomi, M., Bonomo, G., Landoni, F., et al. 2005. Accuracy of CT \& MRI in detection of lymph node involvement of cervical carcinoma. EUR Radiol., 15(12): 2469-74.

Fagundes, H., Perez, Ca., Grigsby, P.W., et al. 1992. Distant metastases after irradiation alone in carcinoma of the uterine cervix. Int. J. Radiat. Oncol. Biol. Phys., 24: 197.

Kim, S.H., Choi, B.I., Lee, H.P., et al. 1993. Preoperative staging of uterine cervical carcinoma: comparison of CT and MRI in 99 patients. J Comput Assist Tomogr., 17(4): 633-640.

Kim, S.H., Choi, B.I., Lee, H.P., et al. 1990. Uterine Cervical Carcinoma: Comparison of CT and MR findings. Radiol., 175: 45-51.
Misciasi, T., Cozza, G., Perrone, L., et al. 2004. Diagnostic imaging in follow up of recurrent cervical carcinoma RAYS, 29(2): 201-8.

Mitchell, D.G., Synder, B., Coakley, et al. 2006. Early invasive cervical cancer tumor delineation by MRI, CT and clinical examination vertified by pathological results J. Clin. Oncol.,20; 24[36]: 5687-84.

Parkin, D.M., Pisani, P., Ferlay, J. 1990. Estimates of the worldwide incidence of 25 major cancers in 1990. Int. J. Cancer, 80: 827.

Piver, M.S., Chung, W.S. 1975. Prognostic significance of cervical lesion size and pelvic node metastases in cervical carcinoma. Obstet. Gynecol., 46: 507.

Togashi, K., Nishimurak, Itoh, K., et al. 1986. Uterine cervical cancer: assessment with high field MR imaging. Radiol.,160: 432-435.

Van Nagell, J.R., Rayburn, W., Donaldson, E.S., et al. 1979. Therapeutic implications of patterns of recurrence in cancer of the uterine cervix. Cancer, 44: 2354.

Walsh, J.W., Goplerud, D.R. 1981. Prospective comparison between Clinical and CT staging in Primary Cervical Carcinoma. AJR, 137: 997.

Whelan, S.L., Parkin, D.M., Masuyer, E. 1990. Patterns of cancer in five continents. Lyons: Int. Agency for Res. Cancer.

Whitley, Vick, C., James, W., Walsh. et al. 1984. CT of the normal and abnormal parametria in Cervical Carcinoma. AJR, 143: 597-603.

\section{How to cite this article:}

Narender Reddy Peddareddy, Santhosh Babu Rendla, Sumalatha Kasturi and Narender GajulA. 2016. MR Imaging of Carcinoma Cervix. Int.J.Curr.Microbiol.App.Sci. 5(7): 619-626. doi: http://dx.doi.org/10.20546/ijcmas.2016.507.069 